\title{
High common childhood illnesses while treatment seeking behavior of mothers'/care givers' was low at rural northwest Ethiopia
}

\author{
Zemene Tigabu Kebede \\ University of Gondar \\ Kassahun Alemu Gelaye \\ University of Gondar
}

Mehari Woldemariam Merid ( $\square$ mehariho19@gmail.com )

University of Gondar

Temesgen Yihunie Akalu

University of Gondar

Ashenafi Tazebew Amare

University of Gondar

Alemayehu Teklu Toni

University of Gondar

Gashaw Andargie Bikis

University of Gondar

Tadesse Awoke Ayele

University of Gondar

Research article

Keywords: Childhood illness, determinants, rural, health seeking behavior, Ethiopia

Posted Date: November 8th, 2019

DOI: https://doi.org/10.21203/rs.2.17005/v1

License: (1) (1) This work is licensed under a Creative Commons Attribution 4.0 International License.

Read Full License 


\section{Abstract}

Background: In most developing countries, childhood illness and deaths are among the most challenging health issues. Most of these deaths were due to preventable causes including acute respiratory infections (ARI), diarrhea, and febrile illnesses. Thus, identification of determinants of these childhood disease illness would help to guide strategic planning, and prioritize interventions. Method: Community based cross-sectional study was conducted. Two stage cluster sampling technique was used to select kebeles and then households. A total of 2,158 mothers/care givers with at least one under-five child were included. Mothers/care-givers were interviewed at their homes using a pretested and structured questionnaire. Adjusted Odds Ratio (AOR) with a 95\% Confidence Interval (Cl) for variables with P-value $<0.05$ in the multivariable model were reported to show significance and direction of association $<0.05$ in the multivariable model were reported to show significance and direction of association. Result: The overall prevalence of childhood illnesses was 16.5\% (95\% Cl: 15.0, 18.2). The treatment seeking behavior of the mothers/caregivers was $22.8 \%$ (95\% Cl: $18.7,27.4)$. Of the illnesses, $6.5 \%$ (95\% Cl: $5.5,6.72)$ were diarrhea, 7.5\% (95\% Cl: 6.5, 8.76) were ARI, and 12.0\% (95\% Cl: 10.66, 13.40) were fever. Mothers' age 40 years and above (AOR=0.35; 95\% Cl: $0.16,0.76)$, mothers' occupation ( $A O R=2.28 ; 95 \% \mathrm{Cl}: 1.84,4.39)$, distance from nearest health center $(A O R=1.02 ; 95 \% \mathrm{Cl}: 1.01,1.03)$, and presence of three or more underfive children in the house (AOR=2.59; $95 \% \mathrm{Cl}: 1.03,5.76)$ were predictors of childhood illness. Conclusion: In this study, the common childhood illness remains high while treatment seeking behavior of the mothers'/care givers' was so low. Mothers' age and occupation, distance from nearest health center, and presence of three or more under-five children in the house were independent determinants of childhood illness. Thus, addressing significant determinants and enhancing mothers'/care givers health seeking behavior would help in reducing morbidity and mortality of under-five children with common childhood illness. Key word: Childhood illness, determinants, rural, health seeking behavior, Ethiopia

\section{Background}

Childhood illnesses including Acute Respiratory Infection (ARI), diarrhea, and febrile illnesses are among the most serious health issues challenging most developing countries. Globally, an estimated 5.9 million children were died before celebrating their $5^{\text {th }}$ birth day in 2015 (1). About $75 \%$ of under-five deaths were caused by diarrhea, fever, and acute respiratory infection combined $(1,2)$ and resulted to the death of 15,000 children daily from these preventable and treatable diseases (3).

Sub-Saharan Africa still experiences remarkably high child mortality rates (4). In 2017, the region had an average under-five mortality rate of 76 deaths per 1,000 live births. About 1 in 13 children dying before his or her fifth birthday which is nearly 14 times higher than the average ratio of 1 in 185 in high-income countries and 20 times higher than the ratio of 1 in 263 in the region of Australia and New Zealand (2).

In Ethiopia, although significant achievements have been made in reducing childhood mortality at the national level, under-five mortality is high in the Amhara region reported as 85 deaths/1,000 live births (5). Acute respiratory infections, diarrhea and malaria were the leading causes of death for children under-five 
years of age $(1,2,6,7)$. Diarrhea contributes to more than one in every ten (13\%) child deaths (8). Furthermore, according to the 2016 Ethiopia Demographic and Health Survey (EDHS) report, about 12\%, $14 \%$, and $7 \%$ of under-five children had diarrhea, fever, and acute respiratory illnesses episode 2 weeks preceding the survey (6)

In developing countries age of child, sex of child, parental educational status, toilet facility, water source, household income, and distance from health facility, maternal characteristics, and number of children per household were significant factors of childhood illness (9-13).

In addition, environmental factors like indoor air pollution, type of cooking fuel, kitchen location, and exposure of children to passive smoking were significantly affect post neonatal illness especially ARI (1419).

Health-seeking behavior is a function not only of the access and availability of health facilities, and other sources of healthcare but also motivation and ability of individuals to seek medical treatment (20). The World Health Organization (WHO) estimates that seeking prompt and appropriate care could reduce child deaths due to acute respiratory infections by $20 \%$ (21). However, significant numbers of children continue to die without appropriate treatment and ever reaching health facility or due to delays in seeking care in developing countries $(22,23)$. In Ethiopia, health care seeking behavior is poor and only a small proportion of children receive appropriate treatment. Nationally, only $33.3 \%$ of under-five children with symptom of acute respiratory infection, $35 \%$ with fever and $44 \%$ with diarrhea were taken to health facility during 5years preceding 2016 (24).

Although different health system initiatives and strategies have been designed and attempted to reduce child mortality in Ethiopia, childhood morbidity and mortality still remain a challenge. Consequently, findings of this study would be useful used for planners, policy makers, decision makers, and as a baseline for researchers for further interventions addressing child morbidity and mortality. Therefore, this study aimed to determine the prevalence of childhood illness and its associated factors in north west Ethiopia.

\section{Methods}

\section{Study design, setting and source population}

Community based cross-sectional study was conducted from March 3-18, 2016 in North Gondar zone, which is located in Amhara region in the northwest part of Ethiopia (18). The zone has 24 districts. According to central statistical agency (CSA) 2017, the estimated population in the North Gondar zone was $3,654,920$. Of which, 858,906 were women in the age ranges between $15-49$ years old (reference). The estimated under-five children were 493,414. As of 2016, the zone has 9 government hospitals, 126 health centers and 563 health posts providing health care services. Mothers/care givers with child age between one and 59 months were included in the study. 


\section{Data collection procedures and variables}

Two stage stratified cluster sampling technique was used to select kebeles and then households. A pretested structured interviewer administered questionnaire was used to collect the data. The questionnaire was translated to Amharic and back translated to English to check the consistency. Mothers/care-givers were interviewed at their homes. In case of more than one child of one and 59 months in the household, data was collected from the last child. Fifty four data collectors and five supervisors, all of them with at least first degree in health sciences were involved in the data collection process. Two days training on the questionnaire, way of interviewing, and ethical issues was given prior to the data collection.

The occurrence of childhood illness during one and 59 months of life and seeking of health care of mothers while the child was sick were the outcome variables. The independent variables were classified as socio-demographic factors including age of mother, marital status, maternal education, maternal occupation, occupation of father, father education, religion, number of sick children, and wealth index; environmental factors were source of water, cook in the house, use of wood, types of toilet facility, and types of cooking fuel; clinical factors including birth weight, pregnancy status, place of last delivery, PNC attendance, home delivery practice, health education by health post, pre-lacteal feeding, initiation of breast feeding, bottle feeding, and pregnancy complication.

In this study, common childhood illnesses include ARI, diarrheal diseases, febrile illnesses, and pain in the ear. Presence of childhood illness was defined as the presence of at least one of the following (cough, diarrhea, fever, or ear pain) two weeks preceding the survey. ARI was defined as the presence of cough and difficulty of breathing which is reported by mothers or care givers within two weeks preceding the survey. Diarrhea was defined as the presence of three or more loose/watery stools per day, or blood in stool as perceived and reported by mothers or care givers within two weeks preceding the survey. Fever was defined as subjective feeling of elevated body temperature reported by mothers or care givers within two weeks preceding the survey. Health care seeking behavior was defined us mothers/caregivers response for signs and symptoms of illnesses to reduce severity and complication after recognizing the child's illness.

\section{Data Processing and Analysis}

The data were entered and cleaned using Epi-Info version 7 and analyzed using STATA version14. Data cleaning, coding and recoding was made. Descriptive statistics in the form of means for continuous variables and percentages for categorical variable were made. Then the findings were presented by tables and texts. Variables with $0.2 \mathrm{p}$-values $\leqq 0.2$ in the bi-variable analysis were fitted in the multivariable model. Adjusted Odds Ratio (AOR) with a 95\% Confidence Interval (Cl) and p-value $<0.05$ in the multivariable model were used to declare significant association with childhood illness. Goodness of fit was checked using Hosmer and Lemeshow test with p-value of 0.37 . 


\section{Results}

\section{Socio-demographic characteristics of mothers/care givers}

The mean $( \pm S D)$ age of mothers/care givers was $27.5( \pm 6.6)$ years. The mean $( \pm S D)$ age of children was $1.5( \pm 1.4)$ years. About $776(33.6 \%)$ of mothers/care givers were in the age group of 30-39 years old. The majority, 2,046 (94.8\%) were married, $1413(65.5 \%)$ of them were uneducated, and 2,126 (98.5\%) of them were orthodox by religion, and (20.0\%) were the poorest by economic status. About $1,069(49.5 \%)$ of fathers were uneducated (Table 1).

Table 1: Socio-demographic characteristics of childhood illness at North Gondar Zone, northwest Ethiopia, 2016. 


\section{Age of women}

15-19

$222(10.3)$

20-24

504 (23.4)

25-29

526 (26.7)

30-39

776 (33.6)

40-49

$130(6.0)$

Marital status

Single

$34(1.6)$

Married

2,046 (94.8)

Divorced

34 (1.6)

Separated

41 (1.9)

Widowed

$3(0.1)$

Occupation of Mother

Farmer

2,024 (93.8)

Merchant

$50(2.3)$

Government employee

$16(0.7)$

Daily laborer

$13(0.6)$

Others

$55(2.6)$

\section{Occupation of father}

Unemployed

Unskilled/daily laborer

$14(0.7)$

Semi-skilled (Farmer\& merchant)

2,085 (96.6)

Skilled/professionals

$28(1.3)$

\section{Educational level of Mother}

Uneducated

$1,413(65.5)$

able to read and write

68 (3.2)

$1-4^{\text {th }}$ grade 
$5-8^{\text {th }}$ grade

279 (12.9)

$9^{-10 \text { th }}$ grade

141 (6.5)

$11-12^{\text {th }}$ grade

$9(0.4)$

Higher education

$13(0.6)$

\section{Father educational status}

Uneducated

1,069 (49.5)

able to read and write

256 (11.9)

$1-4^{\text {th }}$ grade

381 (17.7)

$5-8^{\text {th }}$ grade

$302(14.0)$

$9^{-10 \text { th }}$ grade

117 (5.4)

$11-12^{\text {th }}$ grade

Higher education

$12(0.6)$

$21(1.0)$

\section{Religion}

Orthodox

2,126 (98.5)

Muslim

$32(1.5)$

Wealth index

Poorest

$431(20.0)$

Poor

$432(20.0)$

Middle

$432(20.0)$

Rich

$432(20.0)$

Richest

$431(20.0)$

Number of sick children

One

$279(75.4)$

Two

$82(22.2)$

Three

$9(2.4)$ 


\section{Environmental factors of mothers/care givers}

Regarding on source of water, 917 (42.5\%) of mothers/care givers use piped water. Only $3(0.14 \%)$ mothers/care givers used electric city for cooking. Of mothers/care givers, 1,742 (80.72\%) cooked food inside the home (Table 2).

Table 2: Environmental characteristics of mothers/care givers at North Gondar Zone, northwest, Ethiopia, 2016

\begin{tabular}{ll}
\hline Variables & Frequency (\%) \\
\hline Source of water & $408(18.9)$ \\
River water & $207(9.6)$ \\
Well water & $917(42.5)$ \\
Spring water & $626(29.0)$ \\
Piped water & \\
Use of electric city to cook & $3(0.14)$ \\
Yes & $2,155(99.9)$ \\
No & \\
Cook in the house & $1,742(80.7)$ \\
Yes & $416(19.3)$ \\
No & \\
Use of wood/coal/dung & $2,155(99.9)$ \\
Yes & $3(0.14)$ \\
No &
\end{tabular}

\section{Clinical characteristics of mothers/care givers}

Of the children, 1,475 (68.35\%) were low birth weight. About 1,601 (74.19\%) had wanted pregnancy. Majority of mothers/care givers, 1,027 (64.59\%) delivered at home. Nearly $86 \%$ of mothers/care givers had no any postnatal care service utilization. Only 897 (41.57\%) of mothers/care givers received health education by health extension workers. Of all children, $523(32.91 \%)$ had history of prelacteal feeding practice. Six hundred twenty three (28.87\%) of children had history of bottle feeding (Table 3 ). 
Table 3: Basic characteristics of mothers/care givers and children in North Gondar Zone, northwest Ethiopia, 2016. 


\begin{tabular}{|c|c|}
\hline Variables & Frequency $(\%$ \\
\hline \multicolumn{2}{|l|}{ Birth weight } \\
\hline Low birth weight| & $620(28.7)$ \\
\hline Normal & $1,475(68.4)$ \\
\hline Large & $63(2.9)$ \\
\hline \multicolumn{2}{|l|}{ Was preterm } \\
\hline No & $1,104(96.0)$ \\
\hline \multicolumn{2}{|l|}{ Yes } \\
\hline & $46(4.0)$ \\
\hline \multicolumn{2}{|l|}{ Pregnancy wanted } \\
\hline No & $557(25.8)$ \\
\hline Yes & $1,601(74.2)$ \\
\hline \multicolumn{2}{|l|}{ Place of last delivery } \\
\hline Home & $1,027(64.6)$ \\
\hline Health post & $11(0.7)$ \\
\hline Health center & $419(26.4)$ \\
\hline Hospital & $73(4.6)$ \\
\hline Private clinic/hospital & $4(0.3)$ \\
\hline Other & $56(3.5)$ \\
\hline \multicolumn{2}{|l|}{ PNC attendance } \\
\hline No & $1,370(86.2)$ \\
\hline Yes & $220(13.8)$ \\
\hline \multicolumn{2}{|l|}{ Home delivery practice } \\
\hline No & $1,647(76.3)$ \\
\hline Yes & $511(23.7)$ \\
\hline \multicolumn{2}{|c|}{ Health education by health post } \\
\hline No & $1,261(58.4)$ \\
\hline Yes & $897(41.6)$ \\
\hline \multicolumn{2}{|l|}{ Prelacteal feeding } \\
\hline Yes & $523(32.9)$ \\
\hline
\end{tabular}




\section{Initiation of breast feeding}

With in 1 hour 613 (28.4)

After 1 hour 1,545 (71.6)

Bottle feeding practice

Yes

$623(28.9)$

No

$1,535(71.1)$

Pregnancy complication

No

999 (46.3)

Yes

$1,159(53.7)$

\section{Childhood illness prevalence and health seeking behavior}

The overall prevalence of childhood illnesses among under-five children preceding two weeks of the survey was $16.5 \%(95 \% \mathrm{Cl}: 15.03,18.17)$. The prevalence of childhood diarrhea was estimated as ARI, 7.5\% (95\% Cl: 6.5, 8.8), 6.5\% (95\% Cl: 5.5, 6.7),, and fever, $12.0 \%$ (95\% Cl: 10.7, 13.4). The treatment seeking behavior of the mothers/caregivers for any of the childhood illness was $22.8 \%$ (95\% Cl: 18.7 , 27.4). Of the 370 children of under five years of age who had one or more childhood illnesses, mothers/caregivers sought care at health facilities for, only 63 (45\%), diarrhea 97 (37.6\%), fever, and 17 (10.3\%) of ARI (Table 4).

Table 4: Clinical characteristics among sick post neonatal children in North Gondar Zone , northwest Ethiopia, 2016. 


\begin{tabular}{ll}
\hline Variable & Frequency (\%) \\
\hline Cough/difficulty of breathing & $202(55.0)$ \\
No & $165(45.0)$ \\
Yes & \\
Sought medical treatment for cough & \\
Yes & $17(10.3)$ \\
No & $148(89.7)$ \\
Take home treatment & \\
No & $113(68.5)$ \\
Yes & $52(31.5)$ \\
Outcome of child & \\
Improved & $123(74.6)$ \\
Deteriorated & $23(13.9)$ \\
Other & $19(11.5)$ \\
Child had diarrhea & \\
No & $224(61.5)$ \\
Yes & $140(38.5)$ \\
Had fever & \\
No & $109(29.7)$ \\
Yes & \\
Had pain in the ear & $(70.3)$ \\
No & \\
\hline & \\
Yes & \\
\hline
\end{tabular}

\section{Factors affecting childhood illnesses}

In the bi-variate analysis age of mother, bottle feeding, distance in kilometer from the health center, occupation of mother, wealth index, source of drinking water, cook in the house hold, and number of children in the household were significant determinates of childhood illness. However, in the multivariable analysis, age of mother, distance in kilometer from the nearest the health center, occupation of mother, 
and number of underfive children in the house were significant factors of childhood illness/ post neonatal illness (Table 5).

Table 5: Factors affecting childhood illnesses among mothers/care givers in North Gondar Zone, Northwest Ethiopia, $2018(\mathrm{~N}=2,158)$ 
Variables

\section{Yes (\%) No (\%)}

Distance from the HC
1.02
1.015
$(1.008,1.029)$
$(1.005,1.026)$

Age of mother

$\begin{array}{lllll}15-19 & 31(14.0 \%) & 190(86.0 \%) & 1 & 1 \\ 20-24 & 88(17.5 \%) & 416(82.5 \%) & 1.29(0.8,2.0) & 0.6(0.4,1.1) \\ 25-29 & 99(19.2 \%) & 417(80.8 \%) & 1.27(0.8,2.0) & 0.6(0.4,1.0) \\ 30-39 & 128(17.6 \%) & 598(82.4 \%) & 1.31(0.9,2.0) & 0.7(0.4,1.2) \\ >40 & 11(8.4 \%) & 120(91.6 \%) & 0.56(0.3,1.16) & 0.4(0.2,0.8) \\ \text { Bottle feeding } & & & \\ \text { Yes } & 66(11.1 \%) & 557(88.9 \%) & 1 & 1 \\ \text { No } & 250(16.3 \%) & 1,285(83.7) & 1.71(1.3,2.3) & 0.73(0.5,1.0)\end{array}$

Occupation of mother

Unskilled

Semi-skilled

and

$342(95.79 \%)$

$15(4.21 \%)$

1

1

skilled

$1,750(97.17 \% \quad 51(2.83 \%)$

$1.5(0.8,2.7)$

$2.28(1.8,4.4)$

Wealth index

Poor

149(17.27\%) 714(82.73\%)

$1.2(1.0,1.6)$

$1.01(0.8,1.4)$

Middle

$84(19.44 \%)$

$348(80.56 \%)$

$1.4(1.1,12.0)$

$1.21(0.9,1.7)$

Rich

124(14.37\%) 739(85.63\%) 1

1

Source of drinking

water

Not improved

$210(15.2 \%) \quad 1,175(84.8 \%) \quad 1$

1

Improved

$106(12.7 \%)$

727(87.3\%)

$0.8(0.6, .0)$

$0.81(0.6,1.1)$

Cook in the house 
No

Yes
73(17.55\%)

243(13.95\%)
343(82.5\%)

1,499(86.1)
1

$0.76(0.6,1.0)$
1

$0.8(0.5,1.0)$

\section{Number of children}

$\begin{array}{lllll}\text { One child } & 191(17.1 \%) & 929(83.0 \%) & 1 & 1 \\ \text { Two child } & 117(19.9 \%) & 471(80.1 \%) & 1.21(0.9,1.6) & 1.27(0.9,1.6) \\ \text { Three or more } & 8(33.3 \%) & 16(66.7 \%) & 2.43(1.03,5.8 & \mathbf{2 . 5 9}(\mathbf{1 . 0}, \mathbf{5 . 8}) \\ & & & \end{array}$

The odds of post neonatal illness was decreased by $65 \%$ among 40 years and above mothers compared with 15-19 years. In contrast, the odds of post neonatal illness were increased by nearly $2 \%$ for a unit increase in 1 kilometer from the HC. Moreover, the odds of developing post neonatal illness among semiskilled/skilled mother were 2.3 times compared with unskilled mothers. Mothers having 3 or more children increase the odds of developing post neonatal illness by 2.6 times compared with mothers with single children.

\section{Discussion}

In our study, the overall prevalence of childhood illnesses among under-five children preceding two weeks of the survey was $16.5 \%$. Of the illnesses, $6.5 \%$ were diarrhea, $7.5 \%$ were ARI, and $12.0 \%$ were fever.. When we compared this finding with the reports from Ethiopian Demographic and Health Survey, the prevalence of diarrhea and fever were higher than the national figures (\%?), however the two weeks prevalence of ARI was comparable among children of under five years of age northwest Ethiopia (24).

A Systematic review and meta-analysis conducted in Ethiopia noted that a higher prevalence of childhood illness compared to the current finding. The systematic review included primary studies done in regions with high burden of childhood morbidities including Afar, Somali and rural Dire Dawa where health care access is limited. This might have been attributed for higher pooled prevalence of childhood illness.

Similarly, the result of this study noted lower prevalence of childhood illness compared to some studies conducted elsewhere $(9,11,13,16)$. There could be several explanations for the differences in prevalence of the illnesses with this findings and across literatures. For instance, the study in Tanzania included three remote districts located 200-400 kilometers from the capital of the country. All the three districts were predominantly rural and impoverished with poor transportation, infrastructure, and subsistence agriculture driven economy there by limited availability and poor access to health care services. Likewise, the study done in Kenya was from two slum areas where the majority of the residents seek health care 
outside of health institutions. They mainly visited local drug shops, faith based institutions, and to some extent private clinics. And evidences showed a strong relationship between increased occurrence of childhood morbidity and health seeking behavior outside of health institutions (25-27).

Furthermore, our finding noted lower prevalence of childhood illnesses, particularly childhood diarrhea, compared to different studies conducted at different regions and districts in Ethiopia (28-38). Sample size, year of study, and study setting were some of the factors for the differences in prevalence of childhood illnesses across literatures. For example, one of the studies cited above was conducted in three small kebeles and used only 405 care givers in the study.

The treatment seeking behavior of the mothers/caregivers for any of the childhood illness was $54 \%$. Out of 370 children of under five years of age who had one or more childhood illnesses, mothers/caregivers sought care at health facilities for 63 (45\%), 97 (37.60\%), and 17 (10.33\%)of children for diarrhea, fever, and ARI, respectively. Treatment seeking behavior from health care facilities in this study was consistent for diarrhea and fever but lower for ARI compared to the EDHS 2016 report. The lower care seeking behavior for ARI could be the mothers' perception of mild illness of cough as common cold (39). This study has also noted that the treatment seeking behavior of the mothers/caregivers was lower compared to similar studies done elsewhere $(26,40-43)$. There could be several explanations for the differences in treatment seeking behavior of the mothers/caregivers for common child hood illness. For instance, visiting traditional healer first, financial constraint, perception that illness was not serious and the expectation that illness would recover soon were some of the possible reasons $(25,40,44)$. However, treatment seeking behavior of the mothers/caregivers in our study was higher compared to similar studies conducted in other parts of the country elsewhere $(7,35,45,46)$. The possible reason is that some of the above studies were conducted in relatively urban areas where residents had better socioeconomic status, and good awareness and attitude to seek modern care for their children $(46,47)$.

Different category of factors including maternal socio-demographic characteristics, child related and household environmental factors were significantly associated with childhood illness. Accordingly, maternal age, number of children in the household, mother occupation, and distance from the nearest health center were the independent determinants of childhood illness.

In this study, it was noted a child lived in a family with three and/or more under-five children was more likely to have childhood illness than a household with only one child. This finding was supported with similar studies conducted elsewhere $(36,48-50)$. This could be explained by the fact that when the number of children in the household increases, it is expected that children could be more vulnerable to contamination because the quality of care and attention from parents decreases as mothers become incapable of caring for children. Furthermore, children who get the disease may easily transmit the disease to others who live in the same area.

Moreover, the odds of developing childhood illness among children of semi-skilled/skilled mother occupational status were 2.3 times compared with unskilled mothers. This finding was in agreement with previous studies $(37,50-52)$. This can be justified in that maternal occupation and income are factors 
that provide information about the level of autonomy of the woman that could empower herself to take care of her child $(53,54)$. However, this finding was in contrast with a study done in Ethiopia to determine risks of underfive diarrheal and fever morbidity (55). The possible reason is that mothers with skilled occupation were working at outside of their home and children of those mothers were not received the quality care by the servants/ care giver than were supposed to get from their mothers.

Occurrence of childhood illness was inversely associated with distance to health facility. Children who lived near to health facility received more care at the facility than those who lived far from a health facility $(56,57)$. These finding was also consistent with other data from previous reports $(9,28,58)$. This can be explained by the fact that children living in families located far from health facilities are denied of the availability and get access to the preventive and treatment services for common health problems which in turn led to occurrence increased childhood morbidity.

Finally, this study was not without its limitation. Since data collections were based on mothers/caregivers responses that there could be a room for recall bias. Besides, had limitations about the actual symptoms of illnesses as defined in health care setting and also had gaps with respect to the actual and reported care seeking behavior of mothers/caregivers for childhood illness.

This study was not free of limitations. The morbidity data collected were subjective in the sense that morbidity data were based on the caregivers' perception of illness without validation by medical personnel. Moreover, this study used a recall period for six weeks and data was based on self-reported treatment seeking patterns, thus susceptible to recall bias and social desirability bias.

\section{Conclusion}

In this study, common childhood illnesses remains high while treatment seeking behavior of mothers'/care givers' was so low. Mothers' age and occupation, distance from nearest health center), and presence of three or more under five children in the house) were independent determinants of childhood illness. Thus, addressing significant determinants and enhancing mothers'/care givers health seeking behavior would help in reducing morbidity and mortality of under-five children with common childhood illness.

\section{List Of Abbreviations}

The following are some of the key abbreviations used in this study. ARI-acute respiratory infections, PNCpost natal care, EDHS-Ethiopian demographic and health survey, U5-under five, WHO-world health Organization, AOR-adjusted odds ratio, Cl-confidence interval, SD-standard deviation, EMDHS -Ethiopia Mini Demographic and Health Survey

\section{Declarations}

\section{Ethical consideration}


Ethical approval was obtained from the University of Gondar Institutional Review Board (IRB). Permission letter was obtained from all local administrators and health managers. An informed consent was obtained from mothers/care givers. For mothers/care givers less than 18 years of old, assent was obtained. All study participants were informed that the participation was voluntarily. The potential benefits, harms, the confidentiality, and the possibility of withdrawing from the interview at any time of the interview and after were also informed.

\section{Consent for publication}

Not applicable

\section{Data Availability}

The data used to support the findings of this study are available from the corresponding author upon request.

\section{Conflicts of Interest}

The authors declare they have no competing conflicts of interest.

\section{Funding}

The study has no funding source.

\section{Author contributions}

AT, MW/M, ATT, and GA developed and reviewed the proposal. ZT, KA, TA, TY analyzed and interpreted the patient data regarding the childhood illnesses. KA, M/WM, and TY were the major contributors in writing the manuscript. All the authors have participated in preparing and approving the.

\section{Acknowledgement}

The authors acknowledge all mothers/caregivers of children for their cooperation and willingness. We would also like to thank data collectors for their great collaboration and tolerance for this research work.

\section{References}

1. World Health Organization. World health statistics 2016: monitoring health for the SDGs sustainable development goals: World Health Organization; 2016.

2. World Health Organization. Levels and trends in child mortality. 2018.

3. Hug L, Sharrow D, You D. Levels \& trends in child mortality: report 2017. Estimates developed by the UN Inter-agency Group for Child Mortality Estimation. 2017.

4. Wang H, Liddell CA, Coates MM, Mooney MD, Levitz CE, Schumacher AE, et al. Global, regional, and national levels of neonatal, infant, and under-5 mortality during 1990-2013: a systematic analysis 
for the Global Burden of Disease Study 2013. The Lancet. 2014;384(9947):957-79.

5. World Health Organization. Ethiopia Mini Demographic and Health Survey 2019.

6. Gaither Road, Rockville. Ethiopia Demographic and Health Survey 2016. 2016 Jun. Report No.: 02640325 (Print)

7. Kolola T, Gezahegn T, Addisie M. Health care seeking behavior for common childhood illnesses in jeldu district, oromia regional state, Ethiopia. PloS one. 2016;11(10):e0164534.

8. Organization WH. Global status report on noncommunicable diseases 2014. World Health Organization, 2014.

9. Kante AM, Gutierrez HR, Larsen AM, Jackson EF, Helleringer S, Exavery A, et al. Childhood Illness Prevalence and Health Seeking Behavior Patterns in Rural Tanzania. BMC public health. 2015;15:951.

10. Gebretsadik S, Gabreyohannes E. Determinants of under-five mortality in high mortality regions of Ethiopia: an analysis of the 2011 Ethiopia demographic and health survey data. International Journal of Population Research. 2016;2016.

11. Thiam S, Diene AN, Fuhrimann S, Winkler MS, Sy I, Ndione JA, et al. Prevalence of diarrhoea and risk factors among children under five years old in Mbour, Senegal: a cross-sectional study. Infect Dis Poverty. 2017;6(1):109.

12. Kotloff KL. The burden and etiology of diarrheal illness in developing countries. Pediatric Clinics. 2017;64(4):799-814.

13. Kamal MM, Hasan MM, Davey R. Determinants of childhood morbidity in Bangladesh: evidence from the demographic and health survey 2011. BMJ open. 2015;5(10):e007538.

14. Kanté AM, Gutierrez HR, Larsen AM, Jackson EF, Helleringer S, Exavery A, et al. Childhood illness prevalence and health seeking behavior patterns in rural Tanzania. BMC public health. 2015;15(1):951.

15. Fenn B, Morris SS, Black RE. Comorbidity in childhood in northern Ghana: magnitude, associated factors, and impact on mortality. International journal of epidemiology. 2005;34(2):368-75.

16. Taffa N, Chepngeno G. Determinants of health care seeking for childhood illnesses in Nairobi slums. Trop Med Int Health. 2005;10(3):240-5.

17. Uwemedimo OT, Lewis TP, Essien EA, Chan GJ, Nsona H, Kruk ME, et al. Distribution and determinants of pneumonia diagnosis using Integrated Management of Childhood Illness guidelines: a nationally representative study in Malawi. 2018;3(2):e000506.

18. Sonego M, Pellegrin MC, Becker G, Lazzerini M. Risk factors for mortality from acute lower respiratory infections (ALRI) in children under five years of age in low and middle-income countries: a systematic review and meta-analysis of observational studies. PloS one. 2015;10(1):e0116380.

19. Shibata T, Wilson J, Watson L, LeDuc A, Meng C, La Ane R, et al. Childhood acute respiratory infections and household environment in an eastern Indonesian urban setting. International journal of environmental research and public health. 2014;11(12):12190-203. 
20. Teerawichitchainan B, Phillips J. Ethnic Differentials in Parental Health Seeking for Child Illness in Vietnam. Poverty. Gender and Youth, Population Council, USA. 2007;3.

21. Organization WH. Technical bases for the WHO recommendations on the management of pneumonia in children at first-level health facilities. Geneva: World Health Organization, 1991.

22. Geldsetzer P, Williams TC, Kirolos A, Mitchell S, Ratcliffe LA, Kohli-Lynch MK, et al. The recognition of and care seeking behaviour for childhood illness in developing countries: a systematic review. PloS one. 2014;9(4):e93427.

23. UNICEF. Progress for children: achieving the MDGs with equity: Unicef; 2010.

24. World Health Organization. Ethiopia Demographic and Health Survey. 2016.

25. Umuhoza C, Karambizi AC, Tuyisenge L, Cartledge P. Caregiver delay in seeking healthcare during the acute phase of pediatric illness, Kigali, Rwanda. Pan Afr Med J. 2018;30:160.

26. Wilson SE, Ouedraogo CT, Prince L, Ouedraogo A, Hess SY, Rouamba N, et al. Caregiver recognition of childhood diarrhea, care seeking behaviors and home treatment practices in rural Burkina Faso: a cross-sectional survey. PloS one. 2012;7(3):e33273.

27. Ekpo O. Careseeking for childhood diarrhoea at the primary level of care in communities in Cross River State, Nigeria. Journal of epidemiology and global health. 2016;6(4):303-13.

28. Getu D, Gedefaw M, Abebe N. Childhood diarrheal diseases and associated factors in the rural community of Dejen district, Northwest Ethiopia. American Scientific Research Journal for Engineering, Technology, and Sciences (ASRJETS). 2014;5(1):1-13.

29. Ayele A, Awoke W, Tarekegn M. Crossectional survey; assessment of diarrheal disease prevalence and the associated factors among children under five in Enemay district, northwest Ethiopia. Global Journal of Medical Research. 2014.

30. Regassa G, Birke W, Deboch B, Belachew T. Environmental determinants of diarrhea among underfive children in Nekemte town, western Ethiopia. Ethiopian Journal of Health Sciences. 2008;18(2).

31. Mohammed Al, Zungu L. Environmental health factors associated with diarrhoeal diseases among under-five children in the Sebeta town of Ethiopia. Southern African journal of infectious diseases. 2016;31(4):122-9.

32. Bizuneh H, Getnet F, Meressa B, Tegene Y, Worku G. Factors associated with diarrheal morbidity among under-five children in Jigjiga town, Somali Regional State, eastern Ethiopia: a cross-sectional study. BMC pediatrics. 2017;17(1):182.

33. Gedamu G, Kumie A, Haftu D. Magnitude and associated factors of diarrhea among under five children in Farta wereda, North West Ethiopia. Quality in Primary Care. 2017;25(4):199-207.

34. Mohammed S, Tilahun M, Tamiru D. Morbidity and associated factors of diarrheal diseases among under five children in Arba-Minch district, Southern Ethiopia, 2012. Sci J Public Health. 2013;1(2):102-6.

35. Awoke W. Prevalence of childhood illness and mothers'/caregivers' care seeking behavior in Bahir Dar, Ethiopia: A descriptive community based cross sectional study. Open Journal of Preventive 
Medicine. 2013;3(02):155.

36. Mengistie B, Berhane Y, Worku A. Prevalence of diarrhea and associated risk factors among children under-five years of age in Eastern Ethiopia: A cross-sectional study. Open Journal of Preventive Medicine. 2013;3(07):446.

37. Alambo KA. The prevalence of diarrheal disease in under five children and associated risk factors in Wolitta Soddo Town, Southern, Ethiopia. ABC Research Alert. 2015;3(2).

38. Hashi A, Kumie A, Gasana J. Prevalence of diarrhoea and associated factors among under-five children in Jigjiga District, Somali Region, Eastern Ethiopia. Open J Prev Med. 2016;6(10):233-46.

39. Gelaw YA, Biks GA, Alene KA. Effect of residence on mothers' health care seeking behavior for common childhood illness in Northwest Ethiopia: a community based comparative cross-sectional study. BMC Res Notes. 2014;7:705.

40. Adegboyega AA, Onayade AA, Salawu O. Care-seeking behaviour of caregivers for common childhood illnesses in Lagos Island Local Government Area, Nigeria. Nigerian journal of medicine: journal of the National Association of Resident Doctors of Nigeria. 2005;14(1):65-71.

41. Omore R, O'Reilly CE, Williamson J, Moke F, Were V, Farag TH, et al. Health care-seeking behavior during childhood diarrheal illness: results of health care utilization and attitudes surveys of caretakers in western Kenya, 2007-2010. The American journal of tropical medicine and hygiene. 2013;89(1 Suppl):29-40.

42. Das SK, Nasrin D, Ahmed S, Wu Y, Ferdous F, Farzana FD, et al. Health care-seeking behavior for childhood diarrhea in Mirzapur, rural Bangladesh. The American journal of tropical medicine and hygiene. 2013;89(1 Suppl):62-8.

43. Villarreal I, Turner R, Jo H, Park J, Gemmen E, Pircon JY, et al. Healthcare-seeking behaviour of primary caregivers for acute otitis media in children aged 6 months to $<30$ months in Panama: results of a cross-sectional survey. BMC pediatrics. 2017;17(1):3.

44. Mitiku I, Assefa A. Caregivers' perception of malaria and treatment-seeking behaviour for under five children in Mandura District, West Ethiopia: a cross-sectional study. Malar J. 2017;16(1):144.

45. Abegaz NT, Berhe H, Gebretekle GB. Mothers/caregivers healthcare seeking behavior towards childhood illness in selected health centers in Addis Ababa, Ethiopia: a facility-based cross-sectional study. 2019;19(1):220.

46. Simieneh MM, Mengistu MY, Gelagay AA, Gebeyehu MT. Mothers' health care seeking behavior and associated factors for common childhood illnesses, Northwest Ethiopia: community based crosssectional study. BMC health services research. 2019;19(1):59.

47. Alene M, Yismaw L, Berelie Y, Kassie B. Health care utilization for common childhood illnesses in rural parts of Ethiopia: evidence from the 2016 Ethiopian demographic and health survey. BMC public health. 2019;19(1):57.

48. Mekasha A, Tesfahun A. Determinants of diarrhoeal diseases: a community based study in urban south western Ethiopia. East African medical journal. 2003;80(2):77-82. 
49. Tamiso A, Yitayal M, Awoke A. Prevalence and determinants of childhood diarrhoea among graduated households, in rural area of Shebedino district, Southern Ethiopia, 2013. Science. 2014;2(3):243-51.

50. Woldu W, Bitew BD, Gizaw Z. Socioeconomic factors associated with diarrheal diseases among under-five children of the nomadic population in northeast Ethiopia. Tropical medicine and health. 2016;44(1):40.

51. Zeleke AT, Alemu ZA. Determinants of under-five childhood diarrhea in Kotebe Health Center, Yeka Sub City, Addis Ababa, Ethiopia: a case control study. Global Journal of Medical Research. 2014.

52. Bado AR, Susuman AS, Nebie El. Trends and risk factors for childhood diarrhea in sub-Saharan countries (1990-2013): assessing the neighborhood inequalities. Glob Health Action. 2016;9:30166.

53. Khatab K, Adegboye O, Mohammed TI. Social and Demographic Factors Associated with Morbidities in Young Children in Egypt: A Bayesian Geo-Additive Semi-Parametric Multinomial Model. PloS one. 2016;11(7):e0159173.

54. Mulugeta T. Socio-economic, environmental, and behavioural factors associated with the occurrence of diarrhoeal disease among under-five children, Meskanena Mareko Woreda, southern Ethiopia. Addis Ababa: Addis Ababa University, Ethiopia. 2003.

55. Takele K, Zewotir T, Ndanguza D. Risk factors of morbidity among children under age five in Ethiopia. BMC public health. 2019;19(1):942.

56. Deressa W, Ali A, Berhane Y. Household and socioeconomic factors associated with childhood febrile illnesses and treatment seeking behaviour in an area of epidemic malaria in rural Ethiopia. Trans $\mathrm{R}$ Soc Trop Med Hyg. 2007;101(9):939-47.

57. Akinyemi JO, Banda P, De Wet N, Akosile AE, Odimegwu CO. Household relationships and healthcare seeking behaviour for common childhood illnesses in sub-Saharan Africa: a cross-national mixed effects analysis. BMC health services research. 2019;19(1):308.

58. Bitew BD, Woldu W, Gizaw Z. Childhood diarrheal morbidity and sanitation predictors in a nomadic community. Ital J Pediatr. 2017;43(1):91. 